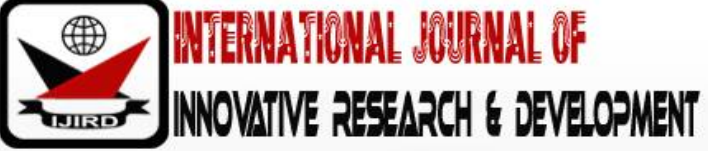

ISSN 2278 - 0211 (Online)

\section{Design and Optimization of System of CSTR for Methanol Production}

Animia Wordu Ajor
Senior Lecturer, Department of Chemical/ Petrochemical Engineering
Rivers State University, Port Harcourt, Nigeria
J. G. Akpa
Senior Lecturer, Department of Chemical/ Petrochemical Engineering
Rivers State University, Port Harcourt, Nigeria
Elenwo Bright Ifeanyi
Research Student, Department of Chemical/ Petrochemical Engineering
Rivers State University, Port Harcourt, Nigeria

\begin{abstract}
:
Mathematical model for design, sizing cum optimization of a system of continuous stirred tank reactor CSTR in series maintaining isothermal process at steady state is unveiled. A methanol chemical production utilizing liquid carbon monoxide at and reacting with liquid hydrogen process conditions a king place in a CSTR in series of three reactors was subjected to an economic analysis [cost] for the best reactor; while taking the kinetic balance effects of the reactors actions and power utilization rate for running the reactors. Sizing the three reactors volume was achieved as basis for good criteria for judgment on the three reactors. The mat-lab version 7.7 Software gave a simulation and profile plots of reaction rate, reactor volume, reactor diameter, mixer revolution, cost of reactor, space time and space velocity against molar conversion rate figures ... And, results obtained showed that molar conversion rate for a single-CSTR higher than a CSTR in series, and is more economical in terms of cost.
\end{abstract}

Keywords: Design, sizing, optimization, isothermal, CSTR in-series, cost, kinetic balance

\section{Introduction}

In our day to day activities as humans, we operate a chemical process in divers' ways but we do not pay attention to its scientific and engineering undertone. A chemical reactor is designed basically to efficiently maximize product formation from a set(s) of reacting feed species (Wordu and Olofu, 2014). These species upon reaction will proceed in certain frequency/ rate through a set of chemical process called chemical kinetics. Chemical reactor configuration started on a very basic level to address the assignment of portraying how to pick, estimate, and decide the ideal working conditions for a reactor whose reason for existing is to deliver wanted items from feed/reactants. [Gavin and Ray, 2008. Chemical designers ensure that the reaction processes proceeds adequately to the formation of desired products in a safe, timely and cost effective fashion. Interestingly, the mathematical models developed from first principles for chemical reactors are practically considerable for most chemically reacting systems.

In recent years, reactor design is confined to simple reactions. However, this research work focused on mathematical model formulations for a single reactor and a one-two reactor arrangement (where the design formulation is based on writing the species balance equations for all the species that participate in the reactions) for dissimilar components. The relationship between several parameters viz reactor volume, space time, space velocity, and cost of the reactor, with respect to a CSTR operation were demystified in relation to their relationship with the conversion rate of a reacting component. The operations of chemical reactors are usually expressed in terms of extensive, system-specific parameters (i.e., reactor volume, molar flow rates). Conversely, the regular methodology utilized in the structure of most activities in substance designing depends on depicting the task regarding dimensionless quantities (Kayode, 2001). Dimensionless formulations have also been taken into account which provided an understanding into the accentuating phenomena that affect the operation, which are generally lost when the analysis borders on case specific (Prabhu and Murali, 2014).

The Design and optimization of chemical reactors is often neglected to simple reactor configurations i.e., batch, tubular, CSTR, with little, which are commonly used in industry to improve the yield and selectivity of the desirable product. These reactor configurations are discussed qualitatively in some textbooks, but no design equations are derived or provided. Most examples cover isothermal reactor operations and non-isothermal operations are sparsely discussed (Aubin et al. 2006). 
This research work presents a different approach to the analysis of chemical reactor operations - reaction based model formulations for dissimilar components rather than the common same species-based design formulation. This work describes an amalgamated mathematical model approach that applies to both single and multiple reactions and an analysis of several parameters in relation to their interaction with a components' molar conversion rate. A validation of the proportionality relationship between reactor volume and product formation for the production of methanol was also presented and an overall result indicated that molar conversion rate for a single CSTR will be more than that for a CSTR in series. Conclusions are stated clearly for different parameters that were considered.

\section{Materials and Methods}

\subsection{Materials}

\subsubsection{Process Description for the Hysys Simulation}

Carbon monoxide and hydrogen were mixed in water (an inert solvent) and charged into the reactor which operates at a maximum temperature of $50^{\circ} \mathrm{C}$ and pressure of $50 \mathrm{kpa}$. The output temperature of the mixer was very low at $125.20 \mathrm{C}$ and was increased with the aid of a heater to the reactor temperature. Upon reaction, the vent product of the reactor was recycled to the mixer to maximize product formation. The reactor operates in the form of a continuous stirred tank reactor CSTR. The liquid outlet of the CSTR is pumped through a valve to maintain pressure. The same procedure described is followed for the CSTR is series of equal volume as shown in the figure below.

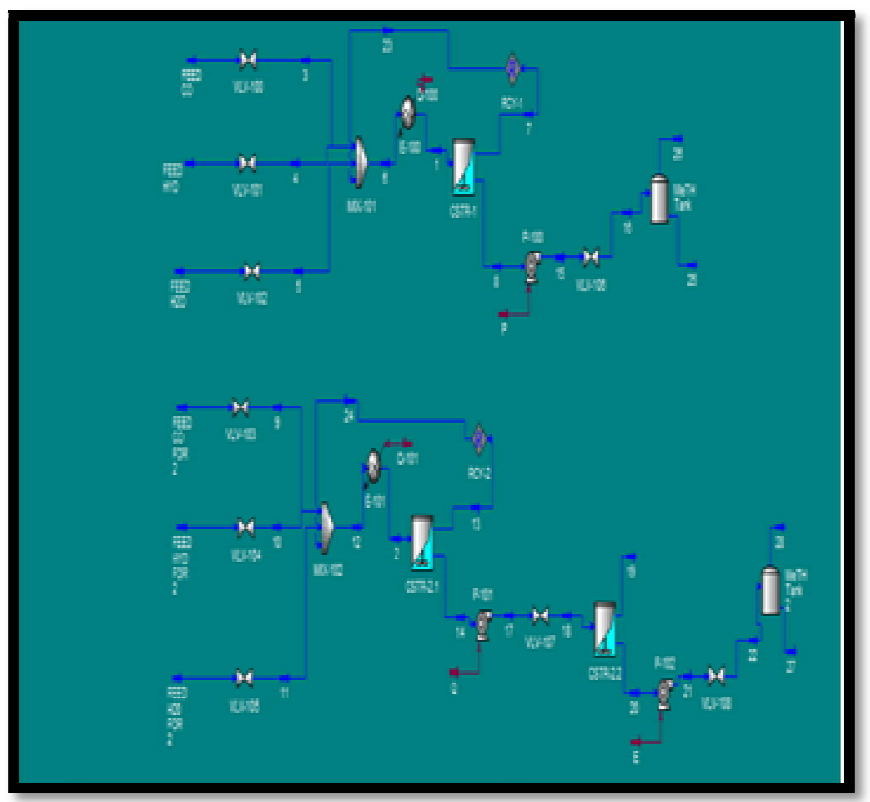

Figure 1: Process Flow Diagram for the Production of Methanol from Hydrogenation of Carbon Monoxide

\subsection{Method}

This research work adopted the use of analytical technique to mathematically develop models for system of CSTR design and sizing while maintaining isothermal conditions for a single CSTR and CSTR in series. The model equations were developed maintaining mass balance principle in equation (1) below;

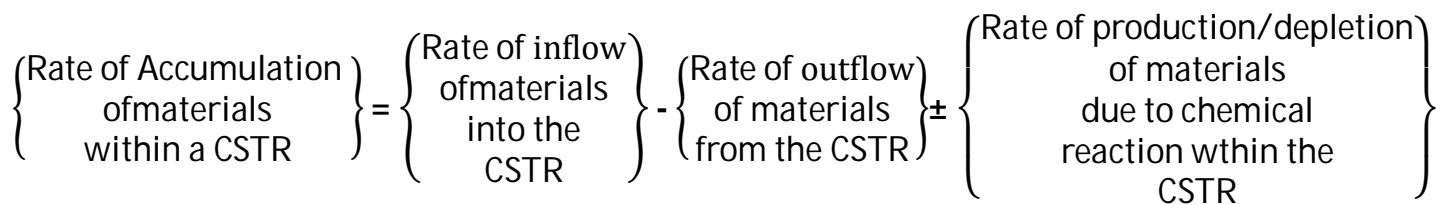

The above equation is applied to an appropriately selected control volume, the largest arbitrarily selected volume of the system in which there are no gradients in composition.

Then, the mass balance of equation [1] can be applied to the whole volume of the reactor recognizing that at steady state process the accumulation term is identically zero and taking a simple reaction involving the hydrogenation of carbon monoxide to produce methanol follows the equation 1 reaction sequence and as adopted where one mole of carbon monoxide reacted with 2 moles of hydrogen to produce one mole of methanol.

$\mathrm{CO}+2 \mathrm{H}_{2}=\mathrm{CH}_{3} \mathrm{OH}$

Where: $\mathrm{A}=$ Carbon monoxide $(\mathrm{CO})$

$\mathrm{B}=$ Hydrogen $\left(\mathrm{H}_{2}\right)$

$\mathrm{P}=$ Methanol $\left(\mathrm{CH}_{3} \mathrm{OH}\right)$

The models developed will be used to derive design equations that will process $3 \mathrm{~m} 3 / \mathrm{h}$ of a reaction mixture in one or two (in series) Continuous flow stirred tank reactors. 
At $50^{\circ} \mathrm{C}$, the kinetic rate expression for the above reaction is (Nicolas, 2012)

$-\mathrm{r}_{\mathrm{A}}=\frac{\mathrm{k}_{1} \mathrm{C}_{\mathrm{A}} \mathrm{C}_{\mathrm{B}}}{1+\mathrm{k}_{2} \mathrm{C}_{\mathrm{A}}}$

Where $\mathrm{k}_{1}=0.1$, and $\mathrm{k}_{2}=0.6$, with concentrations in $\mathrm{kgmol} / \mathrm{m}^{3}$ and rates in $\mathrm{kgmol} / \mathrm{m}^{3} \mathrm{~h}$.

The mixture specific gravity is constant and equal to $1.2 \mathrm{~kg} / \mathrm{dm}^{3}$. The molecular weight of the feed is given to be 40 . The feed contains $10 \mathrm{~mol} \% \mathrm{~A}, 20 \% \mathrm{~B}$ and $70 \%$ inert solvent, S. The liquid viscosity is $0.8 \mathrm{mPa} . \mathrm{s}(\mathrm{cp}$ ) at reaction temperature.

To determine the reactor volume required for one reactors and that for two equal-sized reactors in series for $80 \%$ conversion of $\mathrm{A}$. and if the capital cost of a CSTR unit is given by 20,000 $(\mathrm{V} / 100)^{0.6}$ (where the reactor volume is in $\mathrm{m}^{3}$ ), the life is 20 years with no salvage value, and power costs 3cent per kilo watt-hour, determine which system has the economic advantage. Assume that overhead, personnel, and other operating costs, except agitation, are constant. The operating year is 340 days. Each reactor is baffled (with a baffle with to tank diameter of $1 / 12$ ) and equipped with an impeller whose diameter is one-third the tank diameter. The impeller has a width to diameter ratio $1 / 5$. The impeller is located at one-third the liquid depth from the bottom. The tank liquid-depth-to-diameter ratio is unity.

The assumptions for the process include:

- It is an irreversible isothermal operation

- There is no change in composition

- A constant density process (i.e. volume in equals volume out)

- Steady state

\subsubsection{Kinetic Rate Expression}

$\mathrm{A}+2 \mathrm{~B} \stackrel{\mathrm{k}_{1}}{\rightarrow} \mathrm{P}$

$-r_{A}=\frac{\mathrm{dC}_{\mathrm{A}}}{\mathrm{dt}}=\mathrm{k}_{1} \mathrm{C}_{\mathrm{A}} \mathrm{C}_{\mathrm{B}}$

$\mathrm{C}_{\mathrm{A}}=\mathrm{C}_{\mathrm{AO}}\left(1-\mathrm{X}_{\mathrm{A}}\right)$

$\mathrm{C}_{\mathrm{B}}=\mathrm{C}_{\mathrm{BO}}-\mathrm{C}_{\mathrm{AO}} \mathrm{X}_{\mathrm{A}}$

But, $m=\frac{C_{B O}}{C_{A O}}$

$\mathrm{C}_{\mathrm{B}}=\mathrm{C}_{\mathrm{AO}}\left(\mathrm{m}-\mathrm{X}_{\mathrm{A}}\right)$

$\frac{\mathrm{dC} \mathrm{A}_{\mathrm{A}}}{\mathrm{dt}}=\frac{\mathrm{d}}{\mathrm{dt}} \mathrm{C}_{\mathrm{AO}}\left(1-\mathrm{X}_{\mathrm{A}}\right)=-\mathrm{C}_{\mathrm{AO}} \frac{\mathrm{dX}_{\mathrm{A}}}{\mathrm{dt}}$

Combining equation [4] to [8] into [1] yields:

$\mathrm{C}_{\mathrm{AO}} \frac{\mathrm{d}_{\mathrm{XA}}}{\mathrm{dt}}=\mathrm{k}_{1} \mathrm{C}_{\mathrm{AO}}\left(1-\mathrm{X}_{\mathrm{A}}\right) \mathrm{C}_{\mathrm{AO}}\left(\mathrm{m}-\mathrm{X}_{\mathrm{A}}\right)$

$\mathrm{C}_{\mathrm{AO}} \frac{\mathrm{d}_{\mathrm{XA}}}{\mathrm{dt}}=\mathrm{k}_{1} \mathrm{C}_{\mathrm{AO}}\left(1-\mathrm{X}_{\mathrm{A}}\right) \mathrm{C}_{\mathrm{AO}}\left(\mathrm{m}-\mathrm{X}_{\mathrm{A}}\right)$

$\mathrm{C}_{\mathrm{AO}} \frac{\mathrm{dX}_{\mathrm{A}}}{\mathrm{dt}}=\mathrm{k}_{1} \mathrm{C}_{\mathrm{AO}}^{2}\left(1-\mathrm{X}_{\mathrm{A}}\right)\left(\mathrm{m}-\mathrm{X}_{\mathrm{A}}\right)$

$\frac{\mathrm{dx}_{\mathrm{A}}}{\mathrm{dt}}=\mathrm{k}_{1} \mathrm{C}_{\mathrm{AO}}\left(1-\mathrm{X}_{\mathrm{A}}\right)\left(\mathrm{m}-\mathrm{X}_{\mathrm{A}}\right)$

\subsubsection{Material Balance for CSTR}

The preliminary models for the research will focused on the following:

- Developing the material balance expression for a single reactor, and finding the volume;

- Developing the equation for two reactors in series, and finding their volume;

- Simulation of a simple reaction model for the production of methanol for a single CSTR and a two CSTR in series in Hysys version 7.3 to validate the relationship between reactor volume and product formed;

- Conducting an economic analysis and deciding between the one-and two-reactor systems will feature the required impeller diameter in terms of the $\mathrm{P}$-faudler index.

At steady state, equation [1] gives

$\left\{\begin{array}{c}\text { Rateofinflow } \\ \text { ofmaterial into } \\ \text { the CSTR }\end{array}\right\}=\left\{\begin{array}{c}\text { Rate ofoutflow } \\ \text { ofmaterials from } \\ \text { the CSTR }\end{array}\right\}-\left\{\begin{array}{c}\text { Rate ofdepletion } \\ \text { of materials due } \\ \text { to chemical reaction } \\ \text { within the CSTR. }\end{array}\right\}$

Mathematically, equation [10] gives:

$\mathrm{C}_{\mathrm{AO}}=\mathrm{C}_{\mathrm{A}}+\left(-\mathrm{r}_{1}\right) \tau_{1}$

$-\left(-\mathrm{r}_{1}\right) \tau_{1}=\mathrm{C}_{\mathrm{AO}}-\mathrm{C}_{\mathrm{AO}} \mathrm{X}_{\mathrm{A} 1}-\mathrm{C}_{\mathrm{AO}}$

$\tau_{1}=\frac{\mathrm{C}_{\mathrm{AO}} \mathrm{X}_{\mathrm{A} 1}}{\left(-\mathrm{r}_{1}\right)}$

Substitute equation [9] into [11]

$\tau_{1}=\frac{\mathrm{X}_{\mathrm{A} 1}}{\mathrm{k}_{1}\left(1-\mathrm{X}_{\mathrm{A} 1}\right)\left(\mathrm{m}-\mathrm{X}_{\mathrm{A} 1}\right)}$

Where $\mathrm{X}_{\mathrm{A} 1}=$ fractional conversion for the 1 st reactor

$\mathrm{k}_{1}=$ Rate constant for the reaction.

The material balance expression for a single reactor, and finding its volume yield

$\mathrm{V}=\frac{\mathrm{F}_{\mathrm{AO}}-\mathrm{F}_{\mathrm{A}}}{-\mathrm{r}_{\mathrm{A}}}=\frac{\mathrm{F}_{\mathrm{AO}} \mathrm{X}_{\mathrm{A}}}{-\mathrm{r}_{\mathrm{A}}}=\frac{\mathrm{G}}{-\mathrm{r}_{\mathrm{A}}}$ 
Where,

$\mathrm{V}=$ the volume of material within the reactor

$\mathrm{F}_{\mathrm{AO}}=$ inlet Molar flow rate of Specie $\mathrm{A}$

$\mathrm{F}_{\mathrm{A}}=$ exit molar flow rate

$\mathrm{G}=\mathrm{F}_{\mathrm{AO}} \mathrm{X}_{\mathrm{A}}=$ moles of $\mathrm{A}$ reacted per unit of time

$\mathrm{F}_{\mathrm{A}}=\mathrm{F}_{\mathrm{AO}}-\mathrm{G}$

The problem statement,

$\mathrm{F}_{\mathrm{B}}=\mathrm{F}_{\mathrm{BO}}-2 \mathrm{G}$

From stoichiometry, $\quad \mathrm{F}_{\mathrm{BO}}=2 \mathrm{~F}_{\mathrm{AO}}$

Thus: $\mathrm{F}_{\mathrm{B}}=2\left(\mathrm{~F}_{\mathrm{AO}}-\mathrm{G}\right)=2 \mathrm{~F}_{\mathrm{A}}$ and $\mathrm{F}_{\mathrm{C}}=\mathrm{G}$

The solvent is inert, hence: $\mathrm{F}_{S}=\mathrm{F}_{\mathrm{SO}}$

Recall, the Kinetic Rate expression for the problem statement of equation [2]:

$-r_{A}=\frac{k_{1} C_{A} C_{B}}{1+k_{2} C_{A}}$

$\mathrm{C}_{\mathrm{A}}=\frac{\mathrm{F}_{\mathrm{A}}}{\mathrm{v}_{\mathrm{O}}} \quad$ and $\quad \mathrm{C}_{\mathrm{B}}=\frac{\mathrm{F}_{\mathrm{B}}}{\mathrm{v}_{\mathrm{O}}}$

Hence: $-r_{A}=\frac{k_{1}\left({ }^{F_{A} / v_{0}}\right)\left(\mathrm{F}_{B} / v_{0}\right)}{1+k_{2}\left({ }^{F_{A} / v_{0}}\right)}=\frac{2 k_{1}\left({ }^{F_{A}} / v_{0}\right)}{1+k_{2}\left({ }^{F_{A}} / v_{0}\right)}$

Where,

$\mathrm{v}_{\mathrm{o}}=$ Volumetric flow rate at the outlet [which equals the inlet volumetric flowrate, since the system is of constant density]

Therefore for an $80 \%$ conversion of $\mathrm{A}$

$\frac{\mathrm{G}}{\mathrm{F}_{\mathrm{AO}}}=0.8$

And the total inlet molar flow rate, $\mathrm{F}_{\mathrm{TO}}$, is $10 \% \mathrm{~A}$

i.e. $\mathrm{F}_{\mathrm{AO}}=0.1 \times \mathrm{F}_{\mathrm{TO}}$

$\mathrm{F}_{\mathrm{AO}}\left(\frac{\mathrm{kgmol}}{\mathrm{hr}}\right)=0.1 \times \mathrm{v}_{\mathrm{o}} \times \rho \times\left(\frac{10 \mathrm{dm}}{\mathrm{m}}\right)^{3} \times \mathrm{m}_{\mathrm{w}}$

$\mathrm{F}_{\mathrm{AO}}\left(\frac{\mathrm{kgmol}}{\mathrm{hr}}\right)=0.1 \times \frac{3 \mathrm{~m}^{3}}{\mathrm{hr}} \times \frac{1.2 \mathrm{~kg}}{\mathrm{dm}^{3}} \times\left(\frac{10 \mathrm{dm}}{\mathrm{m}}\right)^{3} \times \frac{1 \mathrm{kgmol}}{40 \mathrm{~kg}}$

$\mathrm{F}_{\mathrm{AO}}\left(\frac{\mathrm{kgmol}}{\mathrm{hr}}\right)=9$

Substituting $\mathrm{F}_{\mathrm{AO}}$ into equation [19] yields:

$\mathrm{G}=\mathrm{F}_{\mathrm{AO}} \times 0.8=9 \times 0.8=7.2 \mathrm{kgmol} / \mathrm{hr}$

Hence, $C_{A}=\frac{F_{A}}{v_{0}}=\frac{F_{A O}-G}{v_{0}}$

This implies that: $V=\frac{G}{-r_{A}}$

Equation for two reactors in series and volume models gives

2.2.3. Model Equations for Two Reactors in Series and Volume

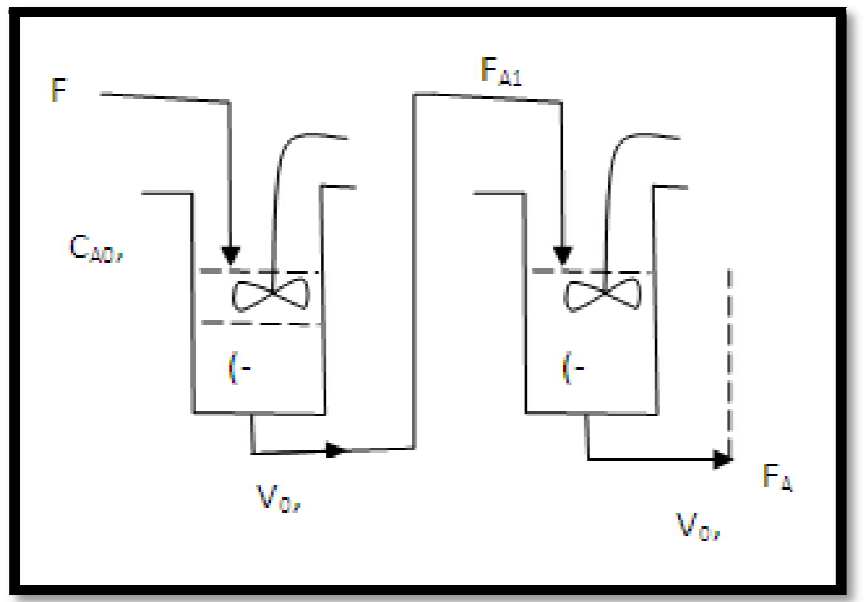

Figure 2: Sketch of CSTR in Series as Per Fractional Conversion

Let $\mathrm{G}_{1}$ and $\mathrm{G}_{2}$ be the fractional conversion in $\mathrm{mol} /$ time for reactor 1 and 2 respectively:

Hence, for an equal-sized reactor,

$$
\mathrm{V}=\frac{\mathrm{G}_{1}}{\left(-\mathrm{r}_{\mathrm{A} 1}\right)}=\frac{\mathrm{G}_{2}}{\left(-\mathrm{r}_{\mathrm{A} 2}\right)}
$$

Where:

$\mathrm{V}_{1}=\mathrm{V}_{2}$ and; 
$\mathrm{G}_{1}=\mathrm{F}_{\mathrm{A} 0} \mathrm{X}_{\mathrm{A} 1}$ and $\mathrm{G}_{2}=\mathrm{F}_{\mathrm{A} 1} \mathrm{X}_{\mathrm{A} 2}$

Noting that

$\mathrm{G}_{1}+\mathrm{G}_{2}=\mathrm{G}$

Where $\mathrm{G}=7.2 \mathrm{kgmol} / \mathrm{h}$

Thus: $\mathrm{G}_{2}=7.2-$

$\frac{\mathrm{G}_{1}}{\mathrm{G}_{2}}=\frac{\left(-\mathrm{r}_{\mathrm{A} 1}\right)}{\left(-\mathrm{r}_{\mathrm{A} 2}\right)}$

$\frac{\mathrm{G}_{1}}{7.2-\mathrm{G}_{1}}=\frac{\left(-\mathrm{r}_{\mathrm{A} 1}\right)}{\left(-\mathrm{r}_{\mathrm{A} 2}\right)}$

$$
\left(-\mathrm{r}_{\mathrm{A}}\right)=\frac{\mathrm{k}_{1}\left({ }_{\mathrm{A}} / \mathrm{v}_{\mathrm{o}}\right)\left(\mathrm{F}_{\mathrm{B}} / \mathrm{v}_{\mathrm{o}}\right)}{1+\mathrm{k}_{2}\left({ }^{\mathrm{F}_{\mathrm{A}} / \mathrm{v}_{\mathrm{o}}}\right)}=\frac{2 \mathrm{k}_{1}\left(\mathrm{~F}_{\mathrm{A}} / \mathrm{v}_{\mathrm{o}}\right)^{2}}{1+\mathrm{k}_{2}\left(\mathrm{~F}_{\mathrm{A}} / \mathrm{v}_{\mathrm{o}}\right)}
$$

$\mathrm{F}_{\mathrm{A}}=\mathrm{F}_{\mathrm{AO}}-\mathrm{G}$

Hence $\left(-r_{A}\right)=\frac{2 k_{1}\left(F_{A O}-G_{1}\right)^{2} / v_{O}^{2}}{1+k_{2}\left(F_{A O}-G_{1}\right)^{F_{A}} / v_{O}}$

Model for Reactor 1

$\mathrm{F}_{\mathrm{AO}}=\mathrm{F}_{\mathrm{A} 1}+\left(-\mathrm{r}_{\mathrm{A} 1}\right) \mathrm{V}_{1}$
$\mathrm{~V}_{1}=\frac{\mathrm{F}_{\mathrm{AO}}-\mathrm{F}_{\mathrm{A} 1}}{\left(-\mathrm{r}_{\mathrm{A} 1}\right)}$
but $\mathrm{F}_{\mathrm{A} 1}=\mathrm{F}_{\mathrm{AO}}-\mathrm{G}_{1}$

but $\mathrm{F}_{\mathrm{A} 1}=\mathrm{F}_{\mathrm{AO}}-\mathrm{G}_{1}$
Hence; $\mathrm{V}_{1}=\frac{\mathrm{F}_{\mathrm{AO}}-\left(\mathrm{F}_{\mathrm{AO}}-\mathrm{G}_{1}\right)}{\left(-\mathrm{r}_{\mathrm{A} 1}\right)}=\frac{\mathrm{G}_{1}}{\left(-\mathrm{r}_{\mathrm{A} 1}\right)}$

Model for Reactor 2

$$
\begin{aligned}
& F_{A 1}=F_{A 2}+\left(-r_{A 2}\right) V_{2} \\
& V_{2}=\frac{F_{A 1}-F_{A 2}}{\left(-r_{A 2}\right)}
\end{aligned}
$$

But, $\quad F_{A 1}=F_{A O}-G_{1}$

$F_{A 2}=F_{A 1}-G_{2}=F_{A O}-G_{1}-G_{2}$

$\frac{F_{A 1}-F_{A 2}}{\left(-r_{A 2}\right)}=\frac{F_{A O}-G_{1}-\left(F_{A 0}-G_{1}-G_{2}\right)}{-r_{A 2}}=\frac{G_{2}}{\left(-r_{A 2}\right)}$

$\left(-r_{A 2}\right)=\frac{k_{1} C_{A 1} C_{B 2}}{1+k_{2} C_{A 2}}=\frac{k_{1}\left(F_{A 0}-G_{1}-G_{2}\right) / v_{0}\left(F_{A 0}-G_{1}-G_{2}\right) / v_{0}}{1+k_{2}\left(F_{A 0}-G_{1}-G_{2}\right) / V_{0}}$

$\left(-r_{A 2}\right)=\frac{2 k_{1}\left(F_{A 0}-G_{1}-G_{2}\right)^{2} / v_{0}^{2}}{1+k_{2}\left(F_{A 0}-G_{1}-G_{2}\right) / v_{0}}$

From the problem statement: $\left(-r_{A 1}\right)=\left(-r_{A 2}\right)$

$\left(-r_{A 2}\right)=\frac{\left(-r_{A 1}\right) G_{2}}{G_{1}}$

Also, $-r_{\mathrm{A} 2}$ can be obtained

$\left(-r_{A 2}\right)=\frac{\left(-r_{A 1}\right)\left(7.2-G_{1}\right)}{G_{1}}$

$\frac{\left(-r_{A 2}\right)}{\left(7.2-G_{1}\right)}=\frac{\left(-r_{A 1}\right)}{G_{1}}$

Combining equation [30] and [33] gives:

$\frac{2 k_{1}\left(F_{A O}-7.2\right)^{2} / v_{0}^{2}}{1+k_{2}\left(F_{A 0}-7.2\right) / v_{0}}=\frac{\left(-r_{A 1}\right)\left(7.2-G_{1}\right)}{G_{1}}$

$\frac{G_{1}\left(2 k_{1}\left(F_{A 0}-7.2\right)^{2} / v_{0}^{2}\right.}{1+k_{2}\left(F_{A 0}-7.2\right) / v_{0}}=\left(-r_{A 1}\right)\left(7.2-G_{1}\right)$

Since $\mathrm{G}_{1}+\mathrm{G}_{2}=$ overall conversion, further simplification yield thus

$\frac{\left(-r_{A 1}\right) G_{1}}{7.2-G_{1}}=\frac{2 k_{1}\left(F_{A 0}-G_{1}\right)^{2} / v_{0}^{2}}{1+k_{2}\left(F_{A 0}-G_{1}\right) v_{0}}$

The above equations [30] and [34] give a cubic equation which will be solved using mat lab ode 45 numerical integration technique.

Simulation of a simple reaction model in Hysys version 7.3 for the production of methanol in a single CSTR and a two CSTR in series in to validate the relationship between reactor volume and product formed

- $\quad$ From the problem statement, the reaction temperature is in a range between $30^{\circ} \mathrm{C}-50^{\circ} \mathrm{C} ; \mathrm{k}_{1}=0.1$ and $\mathrm{k}_{2}=0.6$.

- The reaction expression is: $\mathrm{CO}+2 \mathrm{H}_{2}=\mathrm{CH}_{3} \mathrm{OH}$

- The feed temperature and pressure condition for Carbon monoxide $-191.7^{\circ} \mathrm{C}$ and $6 \mathrm{bar}$; and for Hydrogen is $252.9^{\circ} \mathrm{C}$ and $1 \mathrm{bar}$. The reaction took place in an inert solvent (in this case, water was used at $50^{\circ} \mathrm{C}$ and $1 \mathrm{bar}$ )

- $\quad$ Fluid package - UNIQUAC 
- The stoichiometric coefficient from the reaction expression is Carbon monoxide $=-1$; Hydrogen $=-2$ and Methanol $=1$

- The reaction phase is combined liquid and was carried out in molar basis

- From Arrhenius equation, Activation Energy [Ea] and Arrhenius value [A] were obtained and inputted in the Hysys reaction model for the CSTR.

$\ln A=\ln k+\frac{E_{a}}{R T}$

$\ln \left(\frac{k_{1}}{k_{2}}\right)=\frac{E_{a}}{R}\left(\frac{1}{T_{2}}-\frac{1}{T_{1}}\right)$

\subsection{Economic Analysis}

[Nicolas, 2012] posited that conducting an economic analysis and deciding between the one and two-reactor systems will feature the required impeller diameter in terms of the P-faudler index and this will give an equation of the form utilized in this research:

$$
3 \gamma=\frac{4 n^{3} D_{i}^{2}}{\pi} \psi_{n}\left(\frac{D_{t}}{D_{i}}\right)^{2} \frac{D_{i}}{H_{L}}
$$

Where,

$\gamma=$ The Pfaudler agitation index number

$\mathrm{D}_{\mathrm{i}}=$ required impeller diameter

$\psi_{n}=$ Power number of the impeller

$\mathrm{D}_{\mathrm{t}}=$ Tank Diameter

$\mathrm{H}_{\mathrm{L}}=$ Liquid height

\subsection{Cost for One and Two Reactors Series}

The two costs to be considered are depreciation of capital and power cost for agitation. Using the volumes, 20-years life with no salvage, and the straight-line depreciation method:

For normal mixing, the P-faulder agitation-index (y) number for this low-viscosity fluid is $2 f t^{2} / s^{3}$. Most stirrers are designed for impeller Reynolds numbers of 1000 or greater. For the impeller specified, the power numbers $\propto$, is 0.6 at high Reynolds numbers.

The required impeller diameter, $D_{i}$ may be calculated from the given data. With the liquid height $\mathrm{H}_{\mathrm{L}}$ equal to the tank Diameter, $\mathrm{D}_{\mathrm{t}}$.

$V=\frac{\bar{\lambda} D_{i}^{2}}{4} H_{L}$

But $H_{L}=D_{t}$

$D_{i}=\frac{1}{3} D_{t}$

$V=\frac{\pi D_{t}^{2} D_{t}}{4 \times 3^{2}}=\frac{\pi}{36} D_{t}^{3}$

In terms of the $\mathrm{p}$-faulder index;

$3 y=\frac{4 D_{i}^{2}}{\pi} 4 n\left(\frac{D_{i}}{D_{i}}\right)^{2} \frac{D_{t}}{D_{t}}=n=60 \mathrm{~s} / \mathrm{m}\left\{\frac{3 y \bar{\lambda}}{4 D_{i}^{2}} 4 n\left(\frac{D_{t}}{D_{t}}\right)^{3}\right\}^{1 / 3}$

$=\frac{162.1}{\left(D_{i}\right)^{2 / 3}} \mathrm{r} / \mathrm{min}$

Since $\frac{2 \mathrm{ft}^{2}}{\mathrm{~s}^{3}}=0.186 \mathrm{~m}^{2} / \mathrm{s}^{3}$

The Reynolds Number:

$\operatorname{Re}=\frac{\mathrm{nD}_{\mathrm{i}}^{2} \mathrm{~s}_{\mathrm{L}}}{\mathrm{N}_{\mathrm{L}}}$

39

Where: $\mathrm{D}_{\mathrm{i}}=$ Impeller Diameter, $\mathrm{S}_{\mathrm{L}}$ Liquid density and

$\mathrm{N}_{\mathrm{L}}=$ Viscosity of the liquid.

From the definition of the power Number, we have,

$4 \mathrm{n}=\frac{\mathrm{P}}{\mathrm{P}_{\mathrm{L}} \mathrm{n}^{3} \mathrm{D}_{\mathrm{i}}^{5}}$

(41)

$\mathrm{P}=4 \mathrm{nS}_{\mathrm{L}} \mathrm{n}^{3} \mathrm{D}_{\mathrm{i}}^{5}\left(\mathrm{kgm}^{5} \mathrm{dm}^{-3} \mathrm{~s}^{-3}\right)$

\section{Results and Discussion}

3.1. Rate of Reaction with Molar Conversion The effect of rate of reaction on molar conversion 


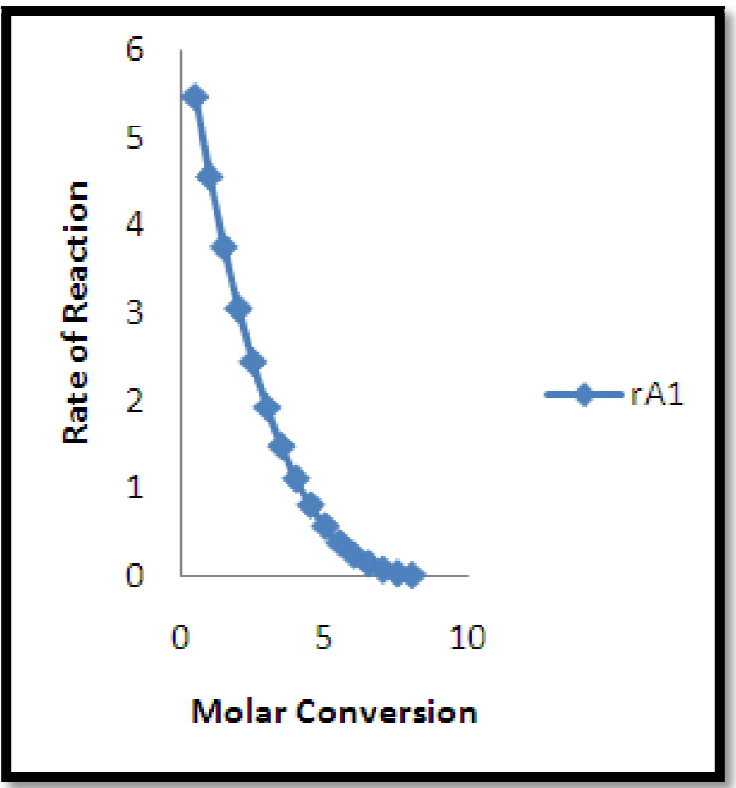

Figure 3: Profile Plot of Rate of Reaction versus Molar Conversion

The rate of reaction is the speed at which a chemical reaction proceeds or the rate at which reactants are converted into products. For most reaction, the rate decreases as the reaction proceeds. The rate of reaction against the molar conversion as shown in figure 3, suggest that the rate of reaction is inversely proportional to molar conversion $\mathrm{G}$. At higher values, of $\mathrm{G}$, lower values of $\left(-\mathrm{r}_{\mathrm{A}}\right)$ are gotten. Maximum yield is at lowest rate of reaction values.

\subsection{Volume of Reactor with Molar Conversion}

The effect of reactor volume on molar conversion rate

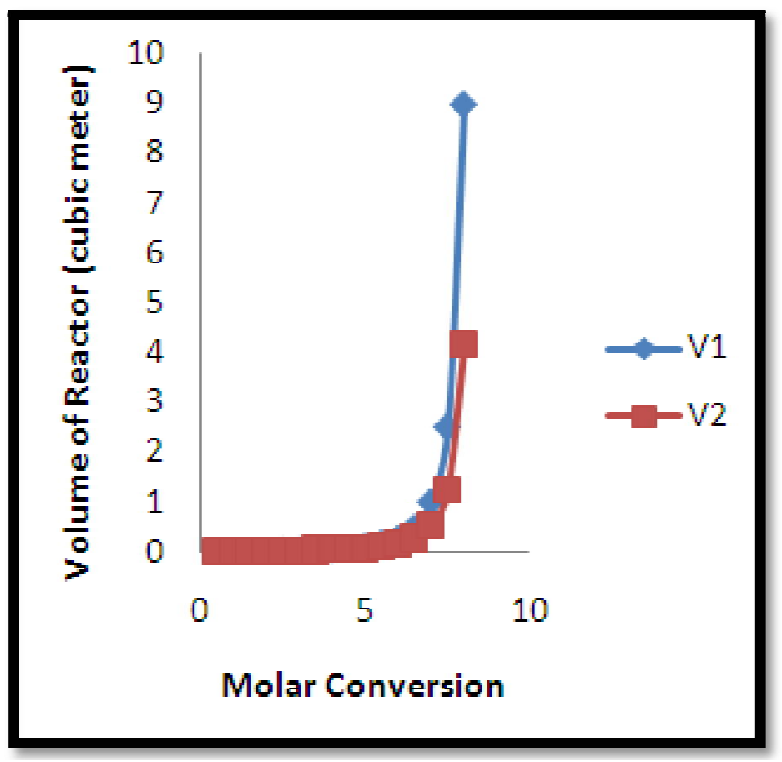

Figure 4: Profile Plot of Volume of Reactor Versus Molar Conversion

A chemical reactor is often an enclosed volume where chemical reaction takes place and more often, conversion of reactant to products in a CSTR is a function of volume at steady state. In Figure 4, the variation of volume of reactors [1 and 2] against molar conversion rate is observed. CSTR in series connection have lower volume of reactor than a single CSTR under same condition. The volume of reactor increases exponentially for the first/second type of reactor, as fractional conversion rate increases. Comparing the volume increase, reactor 2 has a smaller volume increase compared to reactor 1.

\subsection{Mixer Revolution with Molar Conversion}

The effect of mixer revolution on molar conversion rate 


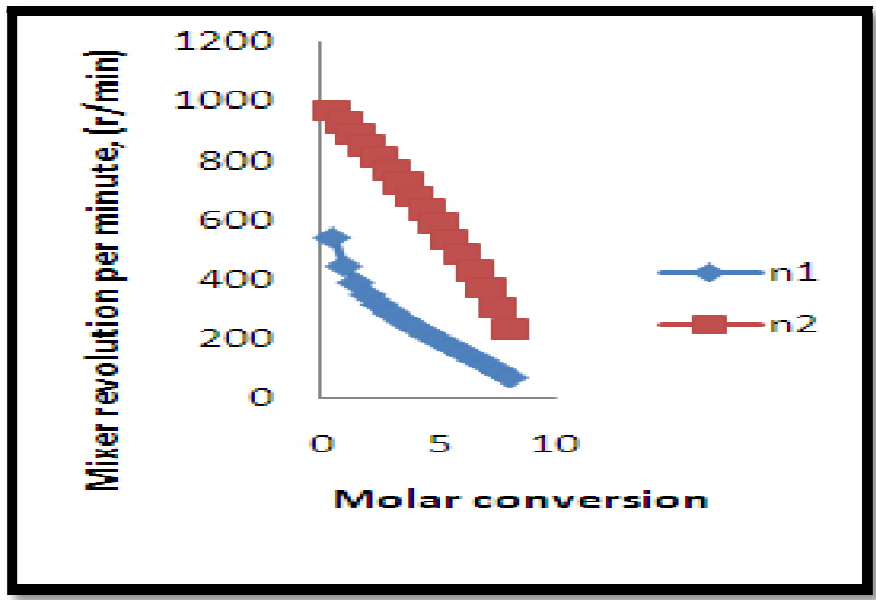

Figure 5: Profile Plot of Mixer Revolution Per Minute versus Molar Conversion

Mixing is an important aspect of a chemical process. When mixing is not present amongst reacting species, little or no reaction will take place. Impellers are used in the mixing process and the type/ speed of impeller used will determine the rate of conversion of reactant(s) to product(s). For low viscous fluid where laminar mixing is present, the diameter of the impeller usually approaches the reactor diameter. Figure 5 depicts rate of mixer revolution with molar conversion rate, G. For both reactors configuration (single and two series reactor), their rate decreases as conversion rate increases. Hence the mixing rate revolution is highest for both at lower $\mathrm{G}$ and lowest at higher $\mathrm{G}$.

3.4. Variation of Liquid Height with Molar Conversion

The effect of liquid height on molar conversion rate

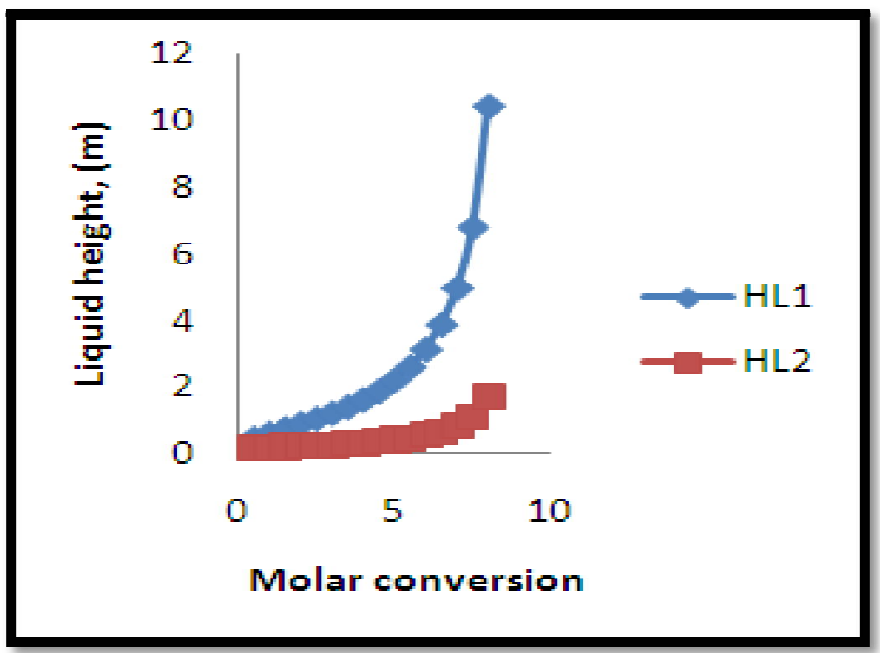

Figure 6: Profile Plot of Liquid Height Against Molar Conversion

Similarly, the height of the liquid varies exponentially as molar conversion rate, G. Generally, the CSTR in series results are lower than single CSTR. The height considered increases exponentially as a function of molar conversion rate. From the Graphs, it starts from $\mathrm{G}=0 ; \mathrm{L}_{\mathrm{i}}=0.1$ and increases to $\mathrm{G}=8$ for reactor 1 and for reactor 2 , when $\mathrm{L}_{\mathrm{i}}=0.2, \mathrm{G}=0.1$ respectively.

\subsection{Variation of Power Output with Molar Conversion}

The effect of power output on molar conversion rate 


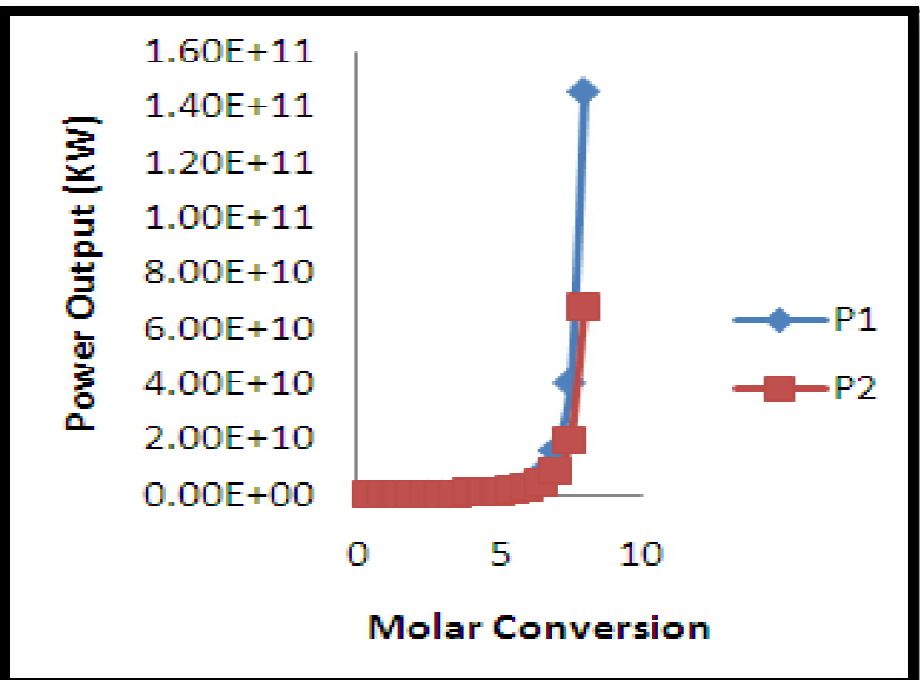

Figure 7: Profile Plot of Power Output Versus Molar Conversion

The work rate of CSTR single and in series determines which is profitable. The higher the work has done by the impeller of the reactor, the higher the energy consumption which culminates into a high power output. Figure 7 shows that the power output of reactor 1 is higher and more profitable than reactor 2 (CSTR in series). Generally, the output increases exponentially for reactor 1 than reactor 2 as $\mathrm{G}$ increases. And the exponential increase is more for reactor 1 than reactor 2 .

\subsection{Variation of Cost of Reactor with Molar Conversion}

The effect of cost of reactor on molar conversion rate

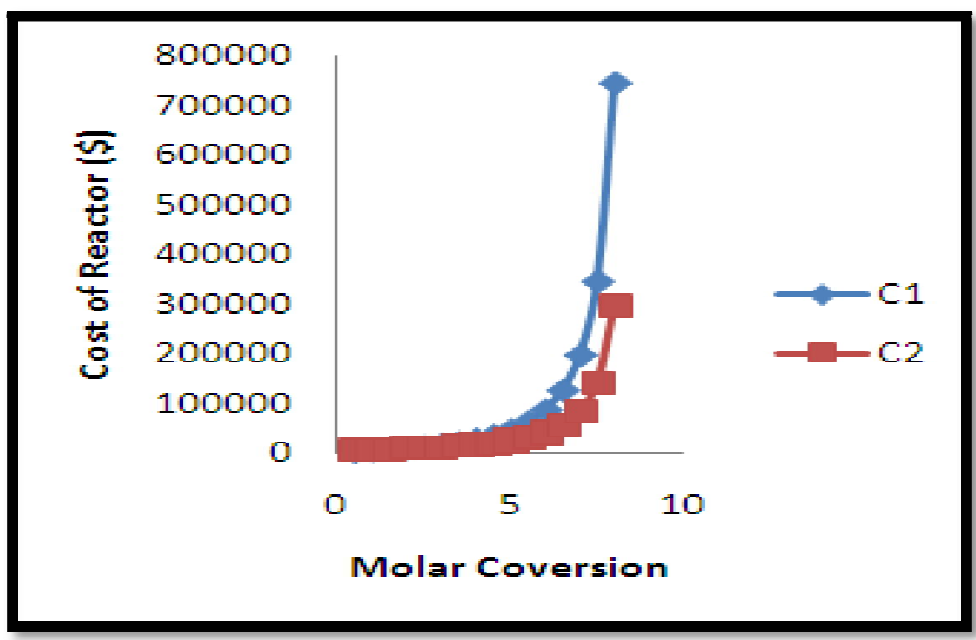

\section{Figure 8: Profile Plot of Cost of Reactor versus} Molar Conversion

The cost of single CSTR and in series determines which is economical. As shown in figure 8 the cost of reactor 1 is higher than reactor 2 (CSTR in series), which presupposes that the CSTR in series will be more economical than a single CSTR when compared to the amount of conversion required.

\subsection{Space Time with Molar Conversion}

The effect of space time on molar conversion rate 


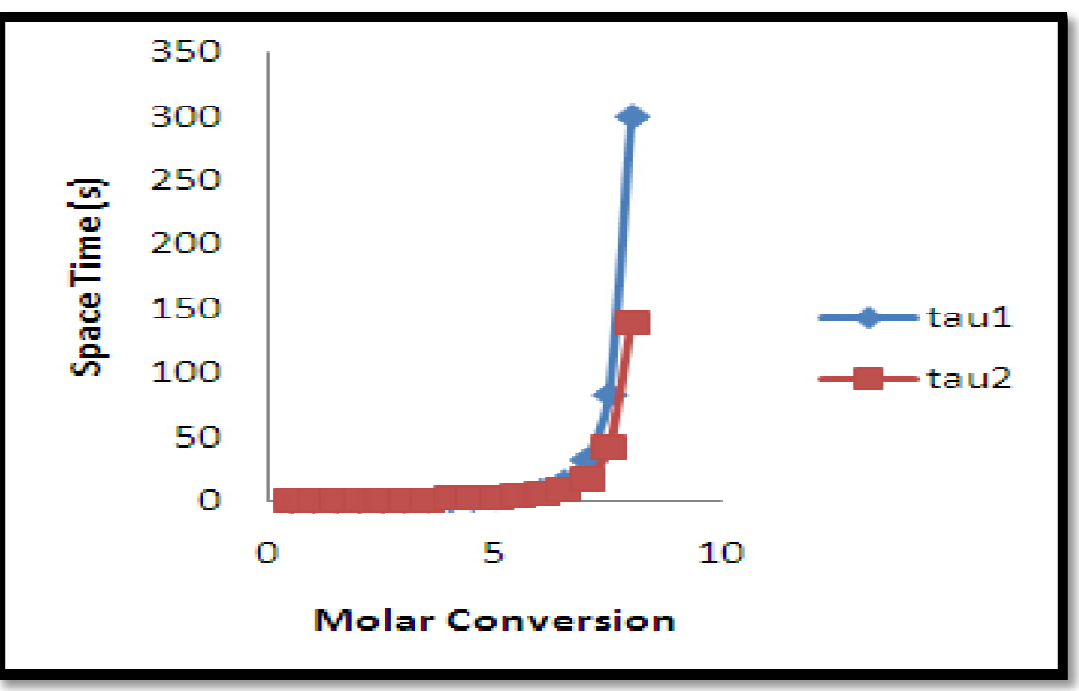

Figure 9: Profile Plot of Space Time versus Molar Conversion

Space time is the time required to process one reactor volume of fluid on initial conditions (Perry et. al., 2008). As shown in figures 9 the space time, $t$, for both reactors increases exponentially as fractional conversion. For a single CSTR, the space time (t) is highest up to 300secs compared to two CSTR in series. In our case, for the two CSTRs in series, the space time is very small say $t=139$ secs when $G=8$. This shows that CSTRs in series have very small space time for conversion of feed to take place than in a single CSTR which requires a higher space time for conversion. The above plot presumes that, the more the connection of CSTRs in series the smaller the space time.

3.8. Variation of Space Velocity with Molar Conversion

The effect of space velocity on molar conversion rate

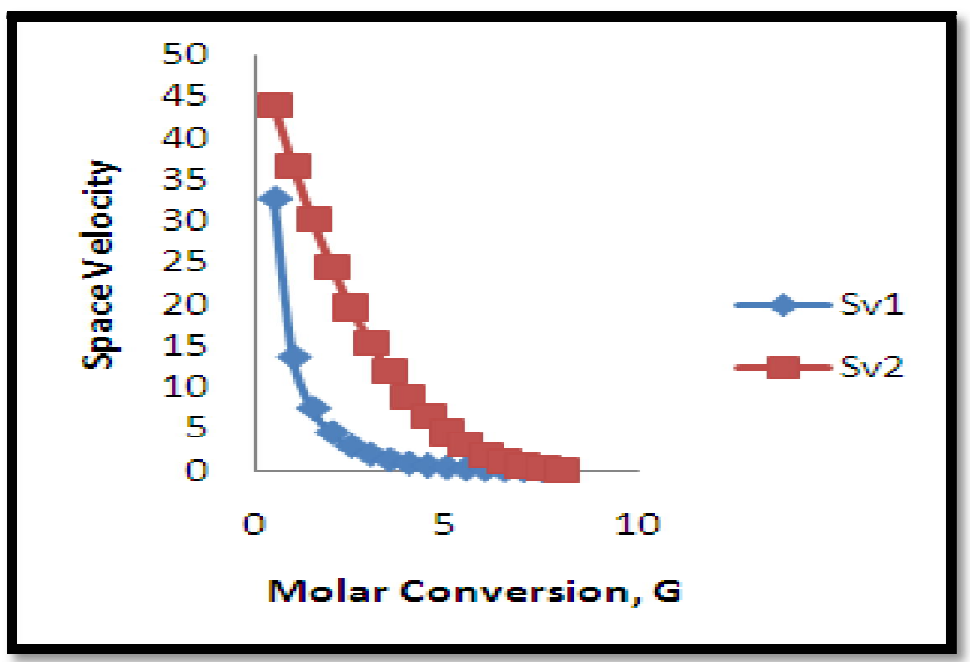

Figure 10: Profile Plot of Space Velocity Versus Molar Conversion

Space velocity is simply an indication of how much of the reactor volume of feed can be treated in a unit time (Octave, 1999). Space velocity as a function of molar conversion rate decreases rapidly to a mere minimum as reactor is best performed. Comparably as shown in figures 10 , for the single CSTR, initially G=0.5, $\mathrm{Sv}_{1}=44.03 \mathrm{~s}^{-1}, \mathrm{~Sv}_{2}=32.75 \mathrm{~s}^{-1}$ and drops to $\mathrm{Sv}_{1}=0.83 \mathrm{~s}^{-1}$ and $\mathrm{Sv}_{2}=8.96 \mathrm{~s}^{-1}$ when Gincreases to 4 . 
3.9. Validation of the Relationship between Reactor Volume and Product Formed

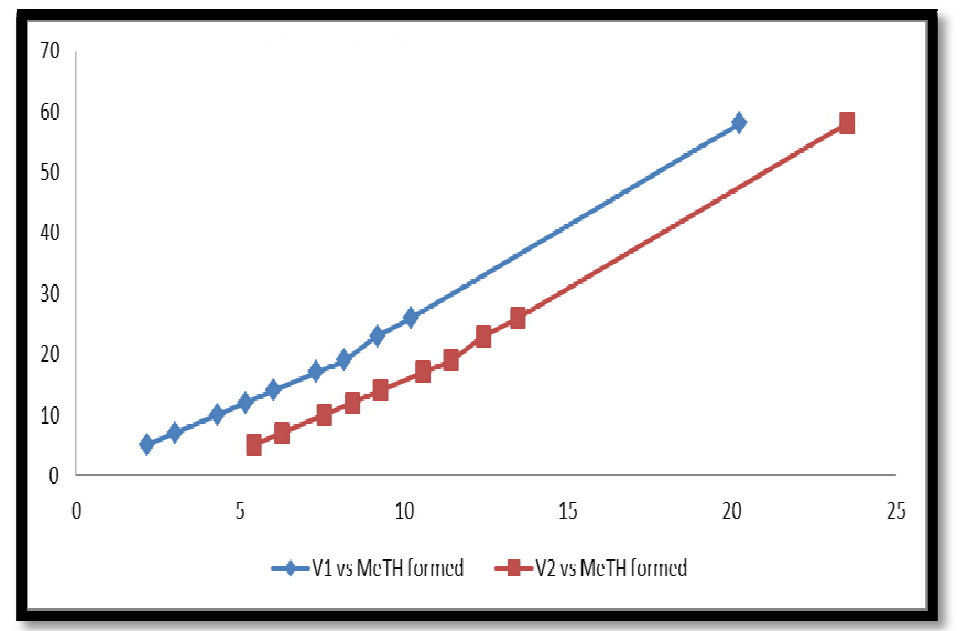

Figure 11: Profile Plot of Reactor Volume versus Methanol Formed

The above plot is a further investigation of the formation of product with respect to the volume of rector which is in agreement with the sizing model equation of proportionality between the volume of reactor and the product formation. The results obtained showed that for every increase in volume of reactor, there is a corresponding increase in the formation of the desired product.

\section{Conclusion}

The research on the sizing and design of CSTR in series is unveiled. The research takes into consideration various works on this area and developed the sizing and functional parameters models and design equations for CSTR single and 2- CSTRs in series using material balance principles. The design model equations were resolved using mat lab ode 45 numerical integration techniques to obtain simulation results. Comparatively volume of single CSTR gave a smaller conversion compared to a two CSTR of equal volume in series and a corroborative simulation for consistencies of results was done using Aspen Hysys. Profitably, CSTR in series will be more economical and will produce a better conversion of reactant(s) than a single CSTR. A single CSTR gives a lower output than CSTR in series. Further investigation suggests that the more the CSTRs are arranged in series, the higher their molar conversion rate (G).

The various profile plots were obtained and discussed carefully and the results were in agreement with the aim and objectives of the research.

\section{Nomenclature}

\begin{tabular}{|c|l|}
\hline $\mathrm{Di}$ & Impeller diameter \\
$\mathrm{HL}$ & Liquid height \\
$\mathrm{Dt}$ & Tank diameter \\
$\mathrm{y}$ & P-faudler agitation index \\
$\alpha, \mathrm{p}$ & Power number \\
$\mathrm{FAO}$ & Inlet molar flowrate \\
$\mathrm{FA}$ & Exit molar flowrate \\
$\mathrm{CAO}$ & Inlet molar concentration \\
$\mathrm{CA}$ & Exit molar concentration \\
$\mathrm{Ra}$ & Rate of reaction \\
$\mathrm{V}, \mathrm{u}, \mathrm{Q}$ & Volumetric flow rate \\
$\tau$ & Reactor space time \\
$\mathrm{k}$ & Rate constant \\
$\mathrm{X}$ & Fractional conversion \\
$\mathrm{NL}$ & Liquid viscosity \\
$\mathrm{SL}$ & Liquid density \\
$\mathrm{E}$ & Activation Energy \\
$\mathrm{U}$ & Internal Energy \\
\hline
\end{tabular}

Table 1

\section{References}

i. Gavin, T. \& Ray, S. [2008] Chemical Engineering Design - Principles, Practice and Economics of Plant and Process Design. ISBN 13: 978-0-7506-8423-1

ii. Kayode, C. [2001] Modelling of Chemical Kinetics and Reactor Design. ISBN: 0-88415-481-5 
iii. Nicolas, P. [2012] Handbook of Chemical Engineering Calculations. Third edition

iv. Octave, L. [1999] Chemical Reaction Engineering. Third Edition; ISBN 0-471-25424-X

v. Perry, R. \& Green, D. [2008] Perry's Handbook for Chemical Engineers, 8th edition

vi. Prabhu, K. \& Murali, V. [2014] Controller Design for Continuous Stirred Tank Reactor using Adaptive Control. Research Journal of Applied Sciences 9(8): 489-495, 2014. ISSN: 1815-932X

vii. Wordu, A. \& Olofu, A. [2016] Design Process of CSTR for Production of Furfuraldehyde. International Journal of Engineering and Technology, 3(1) 1-10. 